\title{
Floor of the mouth hemorrhage subsequent to dental implant placement in the anterior mandible
}

This article was published in the following Dove Press journal:

Clinical, Cosmetic and Investigational Dentistry

\author{
María Peñarrocha-Diago' \\ José Carlos Balaguer-Martí \\ David Peñarrocha-Oltra' \\ José Bagán' \\ Miguel Peñarrocha-Diago' \\ Dennis Flanagan ${ }^{2,3}$ \\ 'Department of Stomatology, University \\ of Valencia, Valencia, Spain; ${ }^{2}$ Department \\ of Dental Medicine, Lugano University of \\ Switzerland, Lugano, Switzerland, ${ }^{3}$ Private \\ Practice, Willimantic, CT, USA
}

Correspondence: Dennis Flanagan Private Practice, 167I Main Street, Willimantic, CT 06226, USA

Tel +I 8604563153

Fax +I 8604568759

Email dffdds@comcast.net

\begin{abstract}
Complications in dental implant surgery are possible. Bleeding complications have been described that may be serious, particularly in the floor of the mouth. We present two cases of sublingual hematomas during dental implant osteotomies that impeded but did not close the airway. The clinical courses of these patient's complications are reviewed. One patient had immediate hematoma formation while the other developed a hematoma overnight, presenting the next day. The treatment rendered was a precautionary in-hospital tracheotomy for the first patient and only compression control for the second. Bleeding complications during dental implant placement in the anterior mandible can be serious issues. There is a potential for sublingual hematoma that could compromise the airway by pressing the tongue against the soft palate into the pharynx. In-hospital treatment may be necessary to prevent an adverse outcome. It must be noted that a hematoma in the submandibular space is life threatening by direct airway compression.
\end{abstract}

Keywords: bleeding, cortical perforation, anastomose, hematoma, complications, osteotomy

Bleeding during dental implant surgery can be a serious complication especially when it occurs in the floor of the mouth and this has been previously reported. ${ }^{1-9}$ The vascular supply to this area is rich and variable. ${ }^{1}$ The lingual artery emanates from the external carotid artery along with the facial artery. At times these are conjoined in a single trunk. The lingual artery courses anteriorly giving off the deep lingual artery, to supply the tongue, and the sublingual artery, to supply the floor of the mouth. Ultimately, the sublingual artery enters the anterior mandible through the lingual cortex (Figures 1 and 2). There may be a single-entry foramen or multiple entry foramina. During a dental implant osteotomy in the anterior mandible an intra-osseous or extra-osseous perforation of the sublingual artery can occur. ${ }^{6,10,11}$ The resulting hematoma can be a serious complication. ${ }^{6}$

A literature search was done for this report and found that the reporting of this complication is not replete, suggesting that it may be uncommon (Table 1). Nonetheless, floor of the mouth bleeding is potentially a life-threatening event and hemorrhage control may require hospitalization and intubation or tracheostomy. ${ }^{2-9}$ If there is deemed a risk for airway compromise, the first priority is to maintain the airway with a tube to avoid a later forced intervention that may create mucosal bleeding that would impair visualization and bleeding down the trachea. 


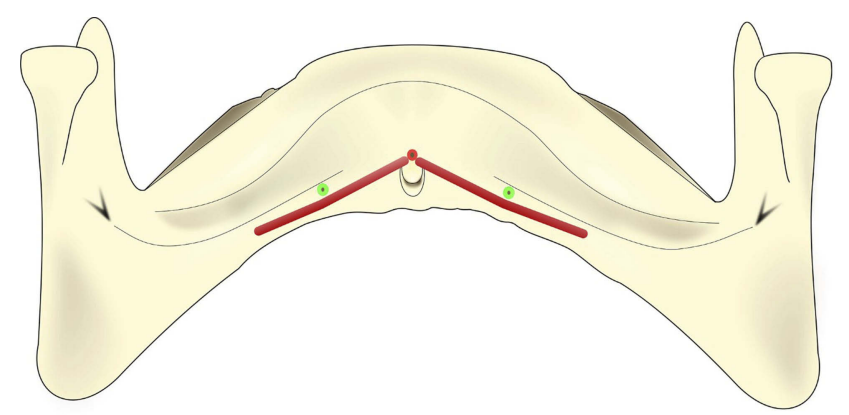

Figure I Schematic drawing of potential locations of the lingual foramina marked in green. The red lines depict the course of the sublingual artery. The lingual foramina can be single or multiple. A large single foramen may contain an artery of significant diameter to cause a significant hemorrhage if severed.

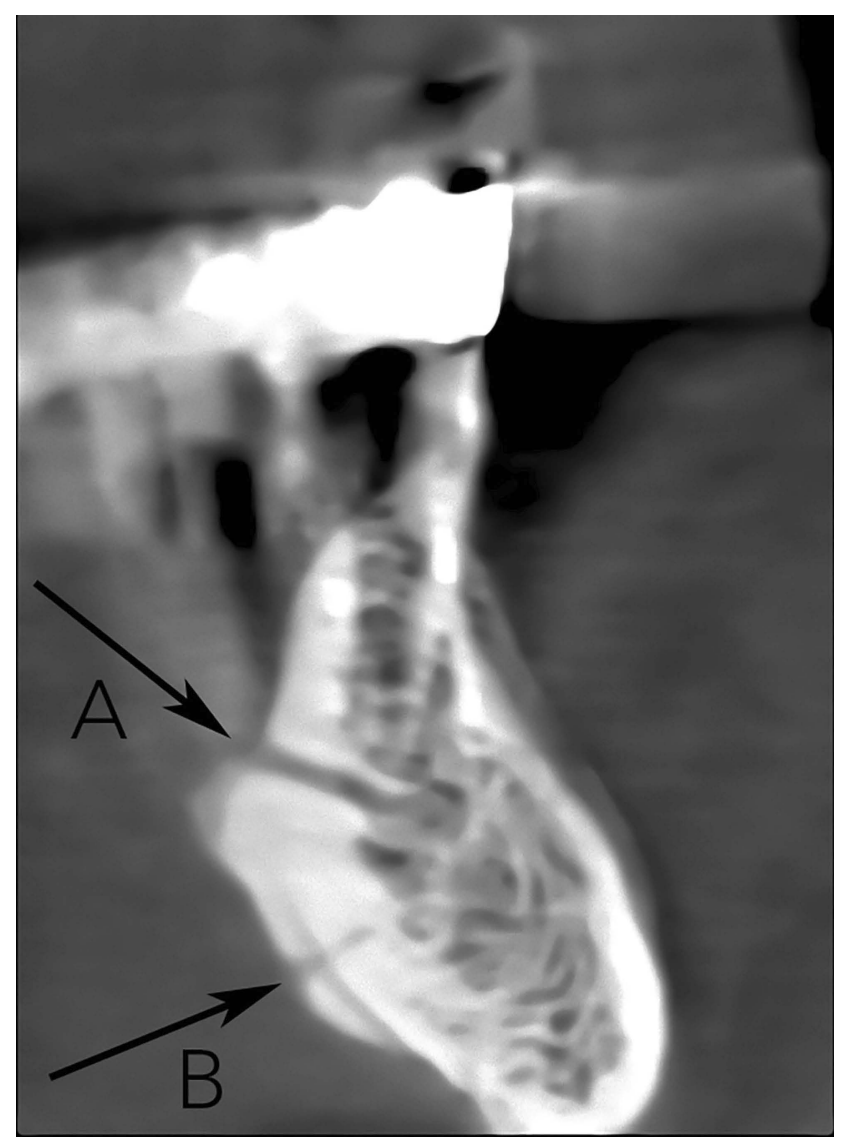

Figure 2 This cone beam computerized tomogram of an anterior mandible shows a slice of the radiographic anatomy of the anterior mandible. Note the lingual canal (A) and the genial tubercle (B).

\section{Case series}

\section{Case I}

A 56-year-old male with an insignificant medical history was referred to the Oral Surgery Division (Valencia University Medical and Dental School, Valencia, Spain), for oral rehabilitation with dental implants. Due to his age, his ASA status was deemed 2.
The patient presented with an ill-fitting and a mandibular complete denture. A comprehensive oral exam, including panoramic radiographs and blood clotting capability were performed. This patient had moderate osseous atrophy of the mandible, so a regenerative procedure was deemed unnecessary for a successful implant retained denture outcome. Treatment options were presented to the patient and a conventional tissue supported mandibular denture with a two implant-retained mandibular overdenture were planned.

Subsequently, the patient was administered $3.6 \mathrm{cc}$ infiltration local anesthesia with articaine $4 \%$ with noradrenalin 1:100,000 (Artinibsa, Laboratorios Inibsa, Granollers, Barcelona, Spain) infiltration, facially and lingually at the anterior mandible.

A mucoperiosteal flap was raised inter-foraminally and the residual ridge was found to be of adequate bone volume to accept Phibo TSA ${ }^{\circledR}$ implants (Phibo Dental Solutions, Sentmenat, Barcelona, Spain) (3.7 mm diameter $X 11.5 \mathrm{~mm}$ length) at sites \#22 and \#28 (Figure 3).

The flap was slightly apically repositioned and sutured to provide increased attached tissue. At this time, a swelling of the floor of the mouth was noted. In less than 20 mins an expanding hematoma forced the tongue against the palate that hindered but did not block normal breathing (Figure 4). The hematoma expansion was controlled with compression.

The patient was taken immediately to a local hospital. Blood testing was done that included hemogram, leukocytic formula, platelets, thrombin time and coagulation hemogram, leukocytic formula, platelets, thrombin time and coagulation) 200-230x10^3 platelets/microliter, coagulation INR (international normalizing ratio) $1(<3)$, and prothrombin time 12 (5$13 \mathrm{sec})$. These values were found to be within normal limits. After careful monitoring for three hours the hematoma did not expand but did not diminish. A tracheostomy was placed between the first and second tracheal rings, the implants were removed as a precaution, and compression was applied. No post-operative CBCT (cone beam computerized tomogram) was able to be taken in this hospital and emerging conditions precluded a CBCT. The hematoma did finally decrease in size the following day, and the patient was discharged after 2 days in good condition. Subsequently the implants were replaced, and a successful overdenture was fabricated.

\section{Case 2}

An 80-year-old male with an unremarkable medical history was referred to our Oral Surgery Division for oral rehabilitation with dental implants. His ASA status was deemed 2. 


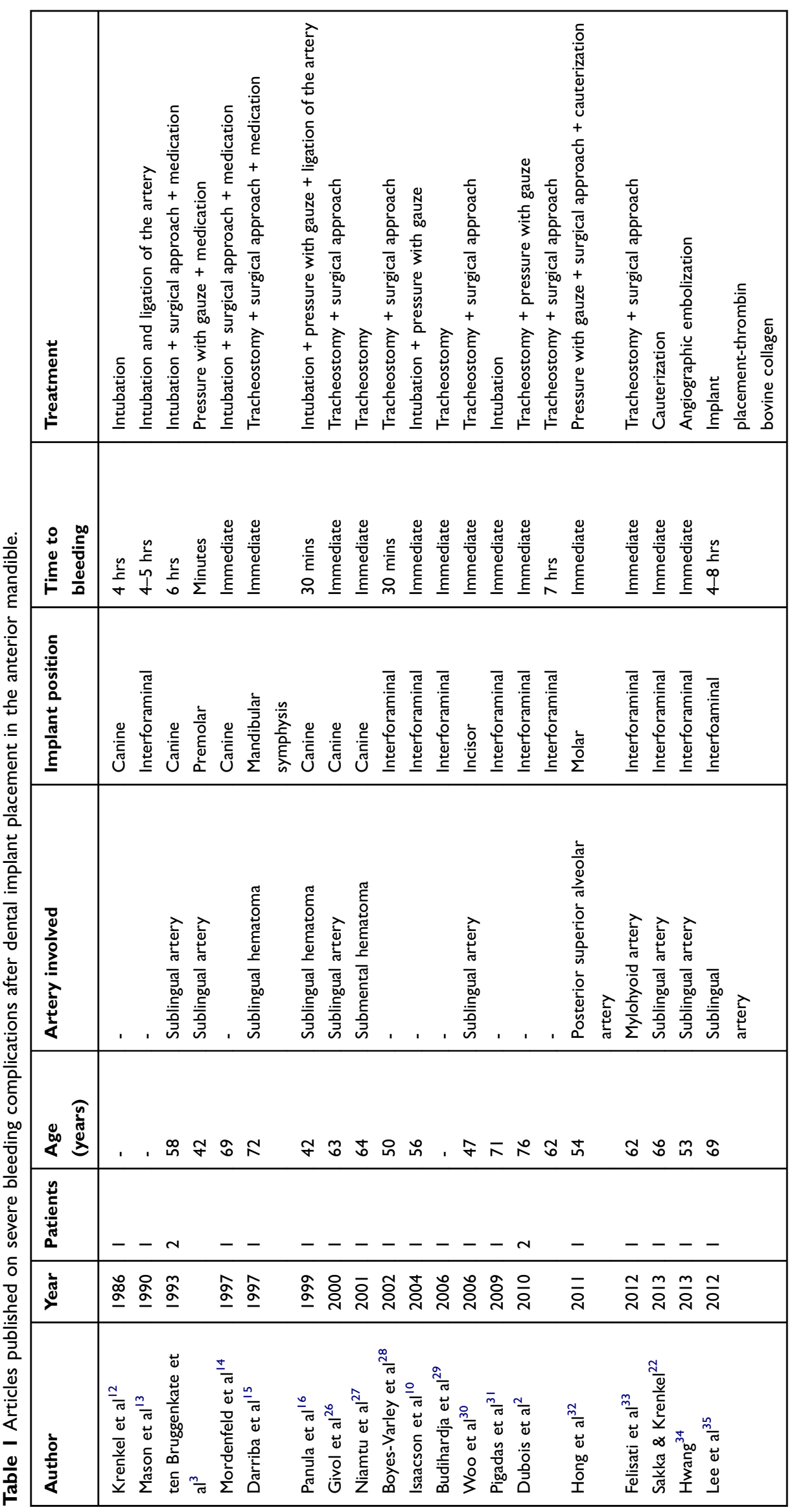




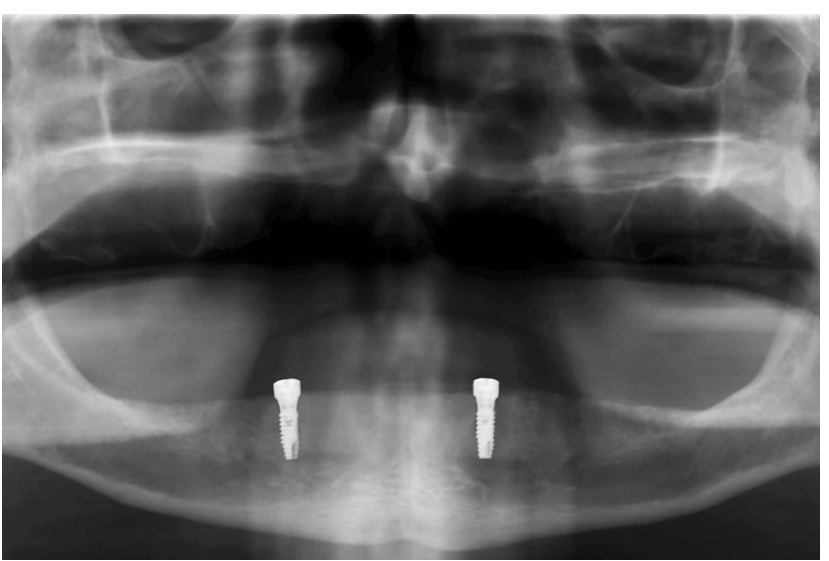

Figure 3 Panoramic radiographic view of the implants placed in Case I. Note the apparent "safe" positions. There was an apparent severance of a branch of the sublingual artery that caused a significant hematoma.

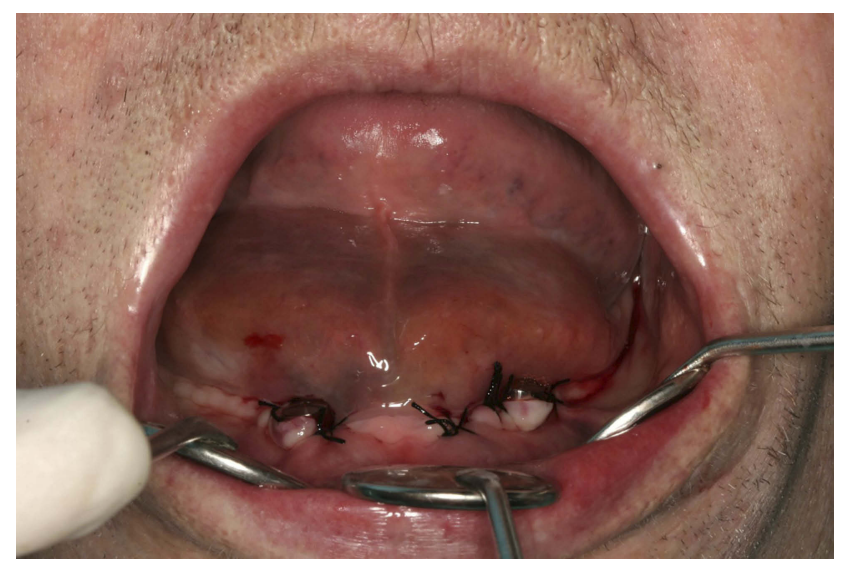

Figure 4 There was an immediate swelling of the floor of the mouth inn Case I that pressed the tongue against the palate but did not compromise respiration. The hematoma was controlled by compression.

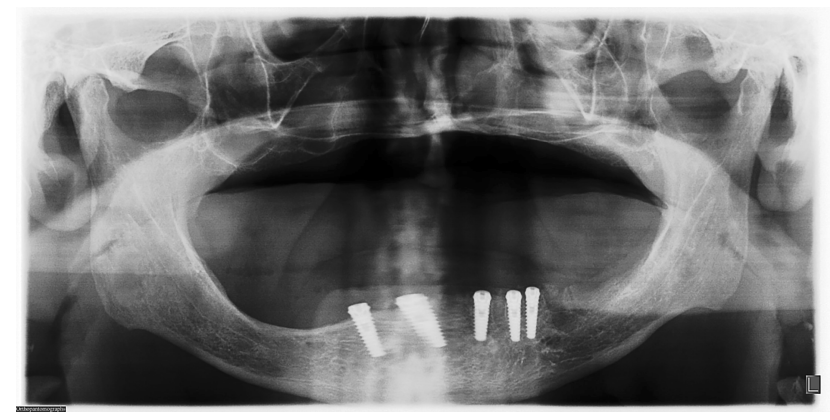

Figure 5 Panoramic radiographic view of the multiple implants placed in the anterior mandible. A subsequent floor of the mouth hematoma formed in this case.

The patient presented with a complete denture in the maxilla and several remaining root fragments in the mandible. The maxillary denture was in satisfactory condition and did not require re-fabrication. In the mandible, the treatment plan was to extract the remaining roots and placement a full arch 6 implant supported implant fixed prosthesis. The mandible had moderate to severe atrophy in the posterior region, but only slight osseous deterioration in the anterior where the implants were to be planned.

$3.6 \mathrm{cc}$ articaine 4\% with noradrenalin 1:100,000 (Artinibsa, Laboratorios Inibsa, Granollers, Barcelona, Spain) infiltration was administered facially and lingually at the anterior mandible.

Adequate attached tissue and bone volume enabled a flapless procedure. Five $3.8 \mathrm{~mm}$ diameter X $13 \mathrm{~mm}$ length implants were placed (Sweden \& Martina, Padua, Italy) in positions \#21, 22, 23, 26 and 29 (Figure 5). One less implant was placed due to a spacing issue during placement. The next day, the patient returned complaining of a floor of the mouth swelling. There was a small non-expanding stable hematoma under the tongue that did not compromise breathing swallowing or speech (Figure 6). On CBCT, the implants did not encroach on the inferior alveolar canal and the lingual cortical plates were found intact (Figure 7). The patient was admitted to a local hospital for compression and observation. The sublingual hematoma resolved spontaneously after $48 \mathrm{hrs}$. The implants were not removed. The patient was subsequently rehabilitated with a full-arch implant-supported fixed prosthesis.

\section{Discussion}

Generally, the anterior mandible is considered a relatively complication free zone for dental implant surgery. Nonetheless, since every patient is not "normal", they may present with non-uniform anatomical features. The prudent implant surgeon should prevent operative issues by thoroughly understanding the anatomy of the operative site. ${ }^{1-8}$ Cone beam computerized tomograms (CBCT) can reveal intra-bony vascular canals that may contain a significant artery. ${ }^{1-8}$ While a pre-operative CBCT is not an absolute necessity, the surgeon should be aware of the patient's anatomy and be prepared to control any incidental arterial hemorrhage.

These cases demonstrate that severe bleeding is possible from implant surgery in the anterior mandible..$^{2-9}$ Although an exploratory dissection was not done, the sublingual artery is the most likely vessel to cause such a serious hemorrhage. The sublingual artery is a terminal branch of the lingual artery which in-turn emanates from the external carotid artery. ${ }^{1}$ The sublingual artery generally penetrates superiorly through the genioglossus muscle (Figure 2). It then courses on to penetrate the lingual surface of the anterior mandible. There may be a single entry or multiple 


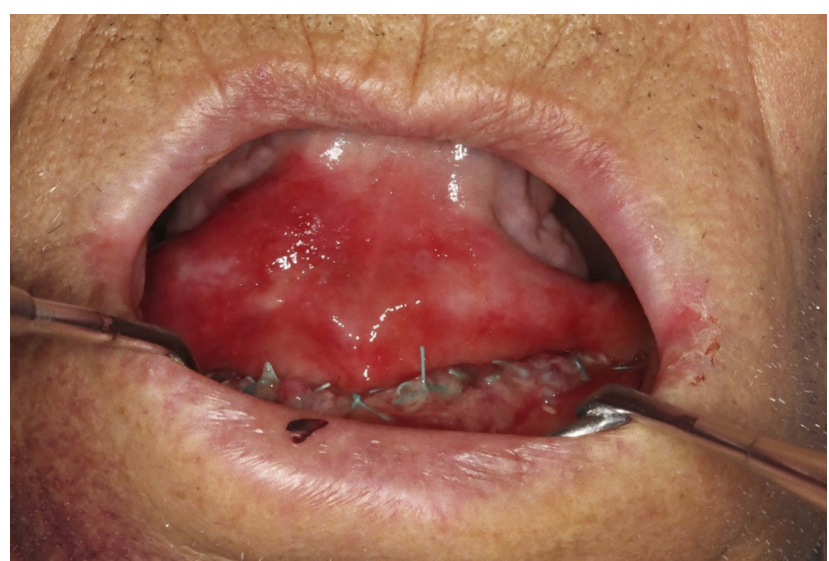

Figure $6 \mathrm{~A}$ hematoma of the floor of the mouth formed after dental implant placement that was reported the following day. Compression was applied, and the swelling resolved after $48 \mathrm{hrs}$.

foramina that emanate. ${ }^{1-9}$ A single entry may have a larger diameter artery and thus more dangerous for a floor of the mouth hemorrhage. While multiple entries may indicate multiple small diameter vessels that may not have significant exsanguination if violated (Figure 1). Vessels as large as $3 \mathrm{~mm}$ in diameter have been measured which if severed could produce a significant hemorrhage. ${ }^{9}$

It is possible for the sublingual artery to be severed intra-osseously, as seen in patient \#2. ${ }^{10,11}$ Figure 7 shows that the implant need not penetrate the lingual cortical plate in order to have a floor of the mouth hemorrhage (Figure 1). The terminus of the sublingual artery is held fast by connective tissue in the foramen (nutrient canal) and thus enables an osteotomy drill to cut it through. ${ }^{9,10}$ The severed proximal artery has a vasospasm and retracts into the floor of the mouth and exsanguinates, creating a hematoma. ${ }^{11}$ This hematoma can be expansive due to anastomosing with contralateral mates and the submental and incisive arteries. ${ }^{2-9}$ The expanding hematoma may impede breathing by forcing the tongue against the soft palate and into the pharynx.
A hematoma emanating from the sublingual artery does not usually connect with the submandibular space as does the submental artery. ${ }^{2-9}$ A truly life-threatening hemorrhage can occur if a hematoma occurs in the submandibular space and expands against the pharynx. This can occlude the airway. The sublingual space is separated from the submental space by the genioglossus and mylohyoid muscles. ${ }^{1}$

In order for the hemorrhage to involve the submental space the nutrient canal would be located inferior to the genioglossus and mylohyoid muscles. The submental space can communicate with the submandibular space posteriorly. ${ }^{1}$ Thus, the patient should be monitored as to the size and expansion rate of any hematoma and for the need of an airway intervention. It may be necessary to maintain the airway with an airway tube to avoid a later forced intervention that may create mucosal bleeding that would impair visualization and bleeding down the trachea. The first patient Case 1 underwent a tracheostomy to secure the airway as a precaution, though the second patient was monitored in hospital until the sublingual hematoma resolved.

In our literature review, most patients were hospitalized and underwent intubation or tracheostomy (Table 1). ${ }^{4}$ An assessment of the hematoma and its rate of expansion should be evaluated before committing to a hospitalization. Nonetheless, a patient's life should not be endangered by underestimating the hematoma. Hospitalization may be required to preclude a fatality.

The submental artery is a branch of the facial artery and travels close to the medial aspect of the mandible. With age and edentulism it may occur directly against the mandibular fossa. Here a lingual perforation may damage the artery and create a life-threatening hemorrhage in the submandibular space.

Previous reports of floor of the mouth bleeding involved implant lengths of 12 and $15 \mathrm{~mm}^{2-9}$ In the cases presented

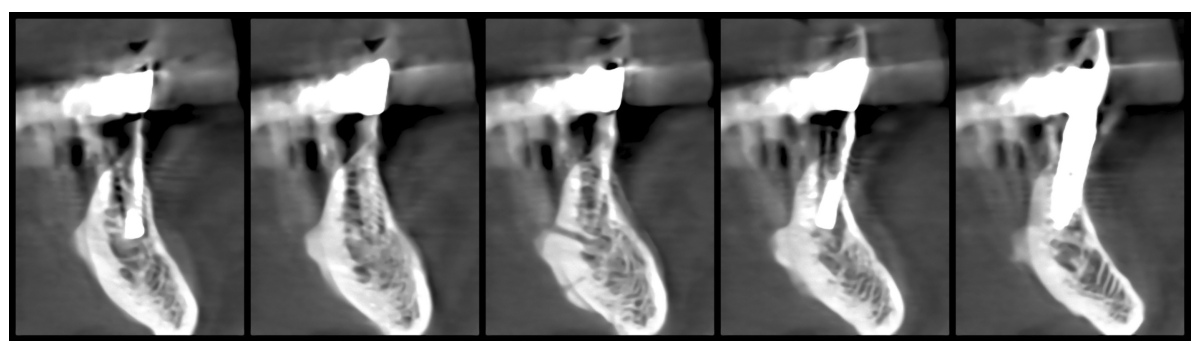

Figure 7 Cone-beam computed tomography of Case 2 shows that the dental implant in position 22 is close to a mandibular lateral lingual canal. A small branch was probably severed to produce the hematoma. 
herein were 11.5 and $13 \mathrm{~mm}$. Nonetheless, relatively long dental implants are not generally needed for adequate support or retention of overdentures or fixed prostheses. ${ }^{17}$ The anterior mandible generally is composed of dense bone that is very supportive for clinical loading of dental implants. However, narrow diameter implants, less than $3 \mathrm{~mm}$, may require much longer length for load resistance. Longer implants may increase the risk for an arterial encounter.

In a literature review of twenty-five reports by Law and coworkers of floor of the mouth hemorrhages, 17 of 21 $(84 \%)$ of cases were the result of lingual cortex perforations. ${ }^{18}$ Management of these were variable and included removal of the implant or aborting of the procedure but most were left in place. Leaving the implant in place prevents blood escaping into the mouth and provides back pressure on the hematoma to induce cessation of the hemorrhage. ${ }^{18}$ Nonetheless, removal of the implant may be done if there is no bleeding through the osteotomy. This may occur if the soft tissue accepts the expanding hematoma volume. Only one case in this review was done with the benefit of preoperative CBCT. This demonstrates the importance of preoperative CBCT examination of the surgical site to help prevent complications. ${ }^{18}$ A post-operative, intra-catastrophe, CBCT may be difficult or impossible to accomplish due to the need for attention to bleeding control. Ascertaining the apical location of the implant may be an academic exercise since the bleeding control is paramount and the artery involved would most likely be the sublingual. Although information may be ascertained, a CBCT at this point may be a distraction.

The intra-osseous incisive artery, the terminus of the inferior alveolar artery, is usually small but anastomoses can contribute for a significant exsanguination. ${ }^{19}$ A severance of this artery may be best managed by simply placing an implant into the osteotomy. The mandible is a closed space and thus would contain the bleed.

Dental implant surgeons should have a thorough knowledge of the anatomical features of a surgical site to avoid operative risks. A CBCT can reveal anatomical structures to be avoided. Vascular nutrient canals may contain significant arteries that can be damaged during an osteotomy. These need to be identified pre-operatively. ${ }^{20}$ Pre-operative planning for an appropriate implant diameter and length can be accomplished on a $\mathrm{CBCT}$. $^{21}$

No attempt was made in these cases to ascertain the exact hemorrhagic culprit. Nonetheless, it may be stated with some confidence, based on CBCT evidence, that these bleeds were indeed originating from the termini of the sublingual arteries.

Bleeding was immediate in the first case and in the second case reported the following day. Other reports show that bleeding can be immediate or not be evident for up to $7 \mathrm{hrs}$ post-operatively. ${ }^{22}$ An arterial transection will cause a vasospasm that slows bleeding and retraction of the artery. ${ }^{4-6,21}$ Coupled with the vasoconstrictors used in local anesthetics, this phenomenon may delay bleeding for several hours. ${ }^{4,22}$

Management of a sublingual hematoma may be to compress it and wait for resolution. ${ }^{5,6}$ Compression would prevent the hematoma from expanding and blocking the airway. Careful monitoring of the airway is important to preclude asphyxiation. The pressure exerted by the enclosing tissues will contain the hematoma and stop further bleeding into the created hematoma space. Compression with ice would help prevent expansion of the hematoma. Any attempt to ligate a severed sublingual artery may result in a severe exacerbation. ${ }^{5,6}$ A dissection for access of this area may invite further exsanguination due to the multiple anastomoses of the nearby arteries. The arterial bleeding would then not be contained. ${ }^{5,6}$ A ligation of the severed floor of the mouth artery is possible but would be extremely difficult due to the exsanguination blocking visualization and complexity of the arterial anastomosing in this area. ${ }^{6}$

In the anterior mandible, it may be best to use narrow diameter implants to minimize the risk for an arterial encounter. The implants may be placed a few millimeters away from the midline to potentially avoid a single large sublingual artery. ${ }^{23-25}$ The bone in the anterior mandible is generally very dense and would be supportive of narrow diameter implants to resist occlusal loading. ${ }^{6}$ The loads in the anterior jaws are generally about a third of those in the posterior. $^{6}$

The sublingual artery typically enters the lingual of the mandible superior to the genial tubercle. ${ }^{1}$ A ridge with substantial height may allow longer implants that would not encounter the artery. With atrophy, the height of the edentulous ridge decreases and the crest approaches the sublingual foramen thus putting the artery in peril of being cut by an implant drill. However, as the osseous atrophy continues the need for vascular supply diminishes and the sublingual artery may atrophy as well. In the anterior mandible, the major vascular osseous supply comes from the facial artery via the periosteal capillaries. ${ }^{6}$ 
A floor of the mouth hemorrhage that is not controlled can result in fatality. ${ }^{5,6,25,26}$ The implant surgeon should be prepared to perform a tracheotomy if the patient does indeed begin to asphyxiate. Generally, the best site to access the trachea is the first tracheal ring. This is superior to the thyroid gland and inferior to the vocal chords. ${ }^{26}$

Law and coworkers published a literature review that found only one case in 25 where there was a preoperative CBCT. ${ }^{18}$ They emphasized the importance of anatomical assessment to prevent surgical complications. ${ }^{18}$

Lee et al, reported a "brisk, pulsatile bleeding from ... the incisive canal" in the mandible which was successfully controlled with a "hemostatic matrix". When there is direct access, use of a directly applied tamponade of a choice of various compositions can be used to control hemorrhage. . $^{6,35}$

Flapless implant placement requires knowledge of the osseous morphology and location of anatomic landmarks. ${ }^{6,11}$

Flapless placement may have fewer complications than open flap procedures due to the pervasive preoperative work-up required.

\section{Conclusions}

The present report describes two cases of bleeding complications after implant osteotomy surgery. These cases highlight the anterior region of the mandible for this kind of complication. Management may entail compression of the hematoma with intra-oral ice packs and monitoring for resolution of the sublingual hematoma according to the severity of the situation. Hospitalization may be indicated. The encasing tissues would contain the hematoma and stop further bleeding. Nonetheless, any expanding hematoma must be contained to prevent blockage of the airway by the tongue being pushed against the palate. The priority is to maintain the airway to prevent a subsequent forced entry, which may itself cause bleeding into the airway, further complicating the problem. Any attempt at a dissection to ligate the cut artery may create more severe bleeding from the local anastomosing arteries.

\section{Ethical approval}

The report of these cases was approved by the University of Valencia, Valencia, Spain.

\section{Informed consent}

Both patients signed written informed consents for treatment and publication of case details.

\section{Author contributions}

All authors contributed to data analysis, drafting and revising the article, gave final approval of the version to be published, and agree to be accountable for all aspects of the work.

\section{Disclosure}

The authors report no conflicts of interest in this work.

\section{References}

1. Standring S. Ed Gray's Anatomy the Anatomical Basis for Clinical Practice. $39^{\text {th }}$ ed. In chief. Edinburgh: Elsevier Churchill Livingstone Chapter 33 Oral Cavity; 2005:583-587.

2. Dubois L, de Lange J, Baas E, Van Ingen J. Excessive bleeding in the floor of the mouth after endosseous implant placement: a report of two cases. Int $J$ Oral Maxillofac Surg. 2010;39:412-415. doi:10.1016/j.ijom.2009.07.062

3. ten Bruggenkate CM, Krekeler G, Kraaijenhagen HA, et al. Hemorrhage of the floor of the mouth resulting from lingual perforation during implant placement: a clinical report. Int J Oral Maxillofac Implants. 1993;8:329-334.

4. Tomljenovic B, Herrmann S, Filippi A, Kühl S. Life-threatening hemorrhage associated with dental implant surgery: a review of the literature. Clin Oral Implants Res. 2015;27(9):1079-1084. doi:10.1111/clr.12685

5. Kalpidis CDR, Setayesh RM. Hemorrhaging associated with endosseous implant placement in the anterior mandible: a review of the literature. J Periodontol. 2004;75:631-645. doi:10.1902/ jop.2004.75.5.631

6. Flanagan D. Important arterial supply of the mandible, control of an arterial hemorrhage, and report of a hemorrhagic incident. J Oral Implantol. 2003;29:165-173. doi:10.1563/1548-1336(2003)029<0165: IASOTM $>2.3 . \mathrm{CO} ; 2$

7. Lamas J, Peñarrocha $M$, Martí E, Peñarrocha $M$. Intraoperative complications during oral implantology. Med Oral Patol Oral Cir Bucal. 2008;13:239-243.

8. Balaguer-Marti JC, Peñarrocha-Oltra D, Balaguer-Martinez J, Peñarrocha-Diago M. Immediate bleeding complications in dental implants: A systematic review. Med Oral Patol Oral Cir Bucal. 2015;20(2):e231-e238. doi:10.4317/medoral.20203

9. Mardinger O, Manor Y, Mijiritsky E, Hirshberg A. Lingual perimandibular vessels associated with life-threatening bleeding: an anatomic study. Int J Oral Maxillofac Implants. 2007;22:127-131.

10. Isaacson TJ. Sublingual hematoma formation during immediate placement of mandibular endosseous implants. J Am Dent Assoc. 2004;135 (2):168-172.

11. Flanagan D. Implants and arteries. $J$ Am Dent Assoc. 2004;135:558. (one page). doi:10.14219/jada.archive.2004.0232

12. Krenkel C, Holzner K. Lingual bone perforation as causal factor in a threatening hemorrhage of the mouth floor due to a single tooth implant in the canine region. Quintessenz. 1986;37:1003-1008.

13. Mason ME, Triplett RG, Alfonso WF. Life-threatening hemorrhage from placement of a dental implant. J Oral Maxillofac Surg. 1990;48:201-204. doi:10.1016/S0278-2391(10)80211-3

14. Mordenfeld A, Andersson L, Bergström B. Hemorrhage in the floor of the mouth during implant placement in the edentulous mandible: a case report. Int J Oral Maxillofac Implants. 1997;12:558-561.

15. Darriba M, Mendonça-Caridad JJ. Profuse bleeding and life-threatening airway obstruction after placement of mandibular dental implants. J Oral Maxillofac Surg. 1997;55:1328-3130. doi:10.1016/S02782391(97)90195-6 
16. Panula K, Oikarinen K, Worthington P. Severe hemorrhage after implant surgery. Oral Surg Oral Med Oral Pathol Oral Radiol Endod. 1999;88:1-3. doi:10.1016/S1079-2104(99)70204-0

17. ELsyad MA, Shaheen NH, Ashmawy TM. Long-term clinical and prosthetic outcomes of soft liner and clip attachments for bar/implant overdentures: a randomized controlled clinical trial. J Oral Rehabil. 2017;44(6):472-480. doi:10.1111/joor. 12500

18. Law C, Alam P, Borumandi F. Floor-of-mouth hematoma following dental implant placement: literature review and case presentation. $J$ Oral Maxillofac Surg. 2017;75(11):2340-2346. doi:10.1016/j. joms.2017.07.152

19. Mardinger O, Chaushu G, Arensburg B, Taicher S, Kaffe I. Anatomic and radiologic course of the mandibular incisive canal. Surg Radiol Anat. 2000;22(3-4):157-161.

20. Kilic E, Doganay S, Ulu M, Çelebi N, Yikilmaz A, Alkan A. Determination of lingual vascular canals in the interforaminal region before implant surgery to prevent life-threatening bleeding complications. Clin Oral Implants Res. 2014;25:90-93. doi:10.1111/clr.2014.25.issue-2

21. Katakami K, Mishima A, Kuribayashi A, Shimoda S, Hamada Y, Kobayashi K. Anatomical characteristics of the mandibular lingual foramina observed on limited cone-beam CT images. Clin Oral Implants Res. 2009;20:386-390. doi:10.1111/clr.2009.20.issue-4

22. Sakka S, Krenkel C. Hemorrhage secondary to interforaminal implant surgery: anatomical considerations and report of a case. J Oral Implantol. 2013;39:603-607. doi:10.1563/AAID-JOI-D-10-00173

23. Tagaya A, Matsuda Y, Nakajima K, Seki K, Okano T. Assessment of the blood supply to the lingual surface of the mandible for reduction of bleeding during implant surgery. Clin Oral Implants Res. 2009;20:351-355. doi:10.1111/clr.2009.20.issue-4

24. Loukas M, Kinsella CR, Kapos T, Tubbs RS, Ramachandra S. Anatomical variation in arterial supply of the mandible with special regard to implant placement. Int $J$ Oral Maxillofac Surg. 2008;37:367-371. doi:10.1016/j.ijom.2007.11.007

25. Lustig JP, London D, Dor BL, Yanko R. Ultrasound identification and quantitative measurement of blood supply to the anterior part of the mandible. Oral Surg Oral Med Oral Pathol Oral Radiol. 2003;96:625-629. doi:10.1016/j.tripleo.2003.08.015
26. Givol N, Chaushu G, Halamish-Shani T, Taicher S. Emergency tracheostomy following life-threatening hemorrhage in the floor of the mouth during immediate implant placement in the mandibular canine region. J Periodontol. 2000;71:1893-1895. doi:10.1902/ jop.2000.71.12.1893

27. Niamtu J. Near-fatal airway obstruction after routine implant placement. Oral Surg Oral Med Oral Pathol Oral Radiol Endod. 2001;92:597-600. doi:10.1067/moe.2001.116503

28. Boyes-Varley JG, Lownie JF. Haematoma of the floor of the mouth following implant placement. SADJ. 2002;57:64-65.

29. Budihardja AS, Pytlik C, Haarmann S, Holzle F. Hemorrhage in the floor of the mouth after second-stage surgery: case report. Implant Dent. 2006;15:148-152. doi:10.1097/01.id.0000223224.79449.30

30. Woo BM, Al-Bustani S, Ueeck B a. Floor of mouth haemorrhage and life-threatening airway obstruction during immediate implant placement in the anterior mandible. Int $\mathrm{J}$ Oral Maxillofac Surg. 2006;35:961-964.

31. Pigadas N, Simoes P, Tuffin JR. Massive sublingual haematoma following osseo-integrated implant placement in the anterior mandible. Br Dent J. 2009;206:67-68. doi:10.1038/sj.bdj.2009.2

32. Hong Y.-H., Mun S.-K. A case of massive maxillary sinus bleeding after dental implant. Int J Oral Maxillofac Surg. 2011;40:758-670. doi:10.1016/j.ijom.2010.11.027

33. Felisati G, Saibene a. M, Di Pasquale D, Borloni R. How the simplest dental implant procedure can trigger an extremely serious complication. Case Reports. 2012;2012:bcr2012007373-bcr2012007373. doi:10.1136/bcr-2012-007373

34. Hwang HD, Kim JW, Kim YS, Kang DH, Kwon TG. Angiographic embolization for hemorrhage control after dental implantation. $J$ Korean Assoc Oral Maxillofac Surg. 2013;39(1):27-30

35. Lee CY, Yanagihara LC, Suzuki JB. Brisk, pulsatile bleeding from the anterior mandibular incisive canal during implant surgery: a case report and use of an active hemostatic matrix to terminate acute bleeding. Implant Dent. 2012;21(5):368-373. doi:10.1097/ ID.0b013e318264d70d
Clinical, Cosmetic and Investigational Dentistry

\section{Publish your work in this journal}

Clinical, Cosmetic and Investigational Dentistry is an international, peer-reviewed, open access, online journal focusing on the latest clinical and experimental research in dentistry with specific emphasis on cosmetic interventions. Innovative developments in dental materials, techniques and devices that improve outcomes and patient satisfaction and preference will be highlighted. The manuscript management system is completely online and includes a very quick and fair peer-review system, which is all easy to use. Visit http://www.dovepress.com/testimonials.php to read real quotes from published authors. 